\title{
Evaluation of factors affecting productivity and profitability of Lohmann Brown layers in a semi-arid environment
}

\author{
Alaster Samkange ${ }^{1 *}$, Erick Kandiwa ${ }^{1}$, Borden Mushonga ${ }^{1}$, Selma A. Amunyela ${ }^{2}$, Alec S. \\ Bishi $^{1}$, Vonai Charamba ${ }^{2}$ and Pricilla Mbiri ${ }^{1}$
}

${ }^{1}$ School of Veterinary Medicine, Faculty of Agriculture and Natural Resources, University of Namibia, P. Bag 13301, Pionierspark, Windhoek, Namibia

\author{
${ }^{2}$ Department of Animal Science, Faculty of Agriculture and Natural Resources, University of \\ Namibia, P. Bag 13301, Pionierspark, Windhoek, Namibia
}

\begin{abstract}
*Corresponding Author: Alaster Samkange, P.O. Box 32376, Pionierspark, Windhoek, Namibia. Phone: +264 81 2429053. E-mail: alastersamkange@ gmail.com; ORCID ID: 00000003-0646-6250
\end{abstract}

\begin{abstract}
A prospective 27-week study investigated the effect of age, ambient temperature, humidity and photoperiod on egg weight and production in Lohmann Brown layers, and thus the profitability of the egg-producing enterprise at a farm in central Namibia, designated Farm A. Overall, age of birds, average temperature, humidity and photoperiod were strongly correlated with mean egg weight $(r=0.84,0.7,-0.51$ and 0.7 , respectively; $p<0.001)$ but there was a weaker correlation of age, temperature, humidity and photoperiod to the number of eggs/bird ( $\mathrm{r}=0.49,0.41,-0.43$ and 0.34 , respectively). Increase in the age of birds, temperature and photoperiod resulted in a significant increase in mean egg weight. A decrease in humidity, however, resulted in a significant increase in mean egg weight. Labour and feed costs contributed $51 \%$ and $14 \%$, respectively, to the overall costs of the enterprise. Egg sales contributed the bulk of the income at $88 \%$, which was followed by the sale of spent layers at $12 \%$.The study concluded that Lohmann Brown layers performed well in the semiarid conditions of central Namibia provided that extreme environmental conditions are avoided. The high input costs, especially labour and feed, were the main constraints to profitability and finding ways to reducing these costs is key to increasing profitability. Increasing the size of the flock is one practical way of offsetting the high labour costs.
\end{abstract}

Keywords: Lohman Brown; layers; productivity; semi-arid environment

\section{INTRODUCTION}

Lohmann Brown is a crossbreed, brown-egg laying chicken (Gallus gallus domesticus) which was selectively bred in Germany (Lohmann Tierzucht, 2018a), from New Hampshires and other brown-egg-laying breeds. According to Lohmann Tierzucht, these birds lay an average of 312-320 eggs per year; their optimal environmental temperature is $18-24{ }^{\circ} \mathrm{C}$; high temperatures can result in reduced feed intake, decreased egg weight, reduced egg production, lower eggshell quality and increased mortality.

Studies from across the world and in recent times have reported that when layer hens of appropriate genetics (Küçükyilmaz et al., 2012) are fed appropriate quantities and quality of feed at the correct age and housed at optimum temperatures and humidity, and are allowed appropriate photoperiod, they produce the highest quantity and best quality of eggs (Farghly 
et al., 2017; Guo et al., 2019; Idowu et al., 2019; John-Jaja et al., 2016; Sallam et al., 2019). Unfavourable environmental conditions compromise the welfare of laying hens (Janczak and Riber, 2015), and the modern consumer of products of animal origin is increasingly preferring products from animals raised under ideal welfare conditions (Cao et al., 2017). Therefore, eggs produced otherwise are at risk of losing markets.

According to some authors, the optimum ambient temperatures vary between $18-26^{\circ} \mathrm{C}$ (Holik, 2010; Hulzebosch, 2019; Kumar et al., 2017; Travel et al., 2011). However temperatures as low as $15^{\circ} \mathrm{C}$ (Kocaman et al., 2006) and as high as $27^{\circ} \mathrm{C}$ (Talukder et al., 2010) have been recommended. Temperatures above $27^{\circ} \mathrm{C}$ negatively affect feed consumption, egg weight and egg quality, especially shell thickness (Oguntunji and Alabi, 2010; Talukder et al., 2010). Previous studies have demonstrated that high ambient temperatures negatively affect growth rate, and the quantity and quality of eggs produced (Oguntunji and Alabi, 2010). This negative influence occurs through a complex interplay of low feed intake and homeostatic failure/malfunction of the cardiovascular, water balance, endocrine, acid/base balance and immune regulatory systems of the bird thereby negatively impacting in part or the whole of the oviposition process (Abbas et al., 2011; Kumar et al., 2017; Oguntunji and Alabi, 2010).

The ideal relative humidity $(\mathrm{RH})$ for layers has been variously mentioned; figures up to $40 \%$ (Kumar et al., 2017), 50-70\% (CocciForum, 2019), and 60-70\%, (Kocaman et al., 2006; Lohmann Tierzucht, 2011; Talukder et al., 2010) have been recommended. According to Kocaman et al., (2006), high relative humidity and temperatures increase the levels of ammonia and encourage the growth of pathogens in poultry houses, thereby predisposing the layers to diseases and compromising egg production. However, low relative humidity may increase water intake if it is coupled with high temperatures.

The influence of light on the physiology of birds through facilitating the ability to easily locate feed (through rods and cones), stimulation of circadian rhythms and setting in motion and regulating the release of reproductive (Johnston, 2004) and other hormones (through photo-receptors in the hypothalamus) is well known (Han et al., 2017; Jácome et al., 2014; Rubinoff, 2014). Layers are photo-stimulated by more than 12 hours of light, regardless of the program of artificial lighting used (Jácome et al., 2014). According to one study involving brown egg-laying breeds, interrupted lighting regimes totalling as low as $4 \mathrm{hr}$ (Han et al., 2017) of total light per day or delivered as flash lights (Farghly et al., 2017) were sufficient to maintain satisfactory egg production when compared to the traditional 14hr/day lighting regime (Skoglund and Whittaker, 1980). However, Lohmann Tierzucht recommend that about 12-14 hours of lighting is sufficient for top egg production in Lohmann Brown layers (Lohmann Tierzucht, 2018b).

A number of studies on laying hens have demonstrated a relationship between the number of eggs, egg weight and the age as well as the weight of poultry (Bharali et al., 2020; Udeh, 2010; Vlčková et al., 2018; Yusuf et al., 2014; Zemková et al., 2007). With few exceptions, egg weights tend to be low at the beginning of the laying period and then increase with age. Large and heavy hens tend to produce larger eggs than small chickens (Etches, 1996). These parameters, in turn, are affected by environmental factors like temperature, relative humidity and photoperiod (Kshash, 2019; Petrus et al., 2019; Sallam et al., 2019). Few articles have attempted to tie environmental factors together to provide the effect of their exact interactions in a single review (Abbas et al., 2011; Jácome et al., 2014; Travel et al., 2011). 
The extent of interactions of environmental conditions and their effect on layer chicken production parameters under extreme weather conditions, which are typical of semiarid central Namibia, has not been explored and reported. In addition, most small-to-medium scale poultry producers lack the capacity to make use of environmentally controlled housing systems for which commercial layers are best suited. This often leaves the birds exposed to extreme weather variations because the poultry house environment in which they are often housed mirror the outside environment.

Farm $\mathrm{A}$ is located in a dry (low humidity) region that is hot during the day $\left(32.5^{\circ} \mathrm{C}\right)$ and cold during the night $\left(5.2^{\circ} \mathrm{C}\right)$ which is typical of semi-arid central Namibia. The farm has kept about 1000 Lohmann brown layers for the past 5 years for agriculture and veterinary student training. The eggs are sold to the university and farm staff. The layer enterprise has so far also acted as a demonstration outpost to surrounding commercial farms as well as rural communities. The production dynamics of this enterprise have never been evaluated in terms of both physiological production parameters and economic viability.

The purpose of this study was to evaluate the suitability of the prevailing environmental factors (temperature, relative humidity and photoperiod) and their interactions with animal factors in so far as they affect productivity in Lohmann Brown layer chickens under the unmitigated open housing conditions at Farm A. The results of this study are expected to shed light on the suitability of open housing system to raise layers in central Namibia, an idea that can be tantalizing for community development practitioners.

\section{MATERIALS AND METHODS}

\subsection{Study area}

Farm A is situated in the Khomas region, 40km east of Windhoek $\left(22^{\circ} 31^{\prime} 0\right.$ " S and $17^{\circ} 15^{\prime} 0^{\prime \prime}$ E), in Namibia, Southern Africa. The farm covers over 10187 hectares of land and is about 1 $963 \mathrm{~m}$ above sea level. The vegetation is predominantly savannah dominated by shrub-veld (Mendelsohn et al., 2002). The climate is semi-arid with average annual rainfall figures which range between 300-400mm (Kandiwa et al., 2018). During summer, the average maximum temperatures reach around $30^{\circ} \mathrm{C}$ and minimum temperatures in winter can dip as low as $7^{\circ} \mathrm{C}$ at night (Info-Namibia, 2018).

\subsection{Study birds}

The study subjects were 1000 Lohmann Brown layers sourced at point-of-lay (19 weeks of age) from a South African breeder. The birds were housed in groups of five per cage in 200 standard battery cages. They were fed on $125 \mathrm{~g}$ per bird of a layers' ration from Feedmaster Namibia (15\% CP, 3.8\% Ca and $0.46 \%$ P). Drinking water was supplied ad lib from a reservoir through a nipple drinker system. The study was terminated when the birds were 45 weeks old. In this study the birds were kept well ventilated under natural lighting without additional artificial lighting. The enterprise, however, kept the birds in production for up to 70 weeks of age at which point they were sold as off-layers. The ungraded eggs were sold locally at a subsidized price to staff and students.

\subsection{Study Design}

The study was a 27-week observational prospective investigation of the effect of age, temperature, humidity and photoperiod on production parameters (eggs/bird and egg weight) of Lohmann Brown layers. Daily temperatures were measured by a maximum/minimum thermometer suspended in the poultry house. A thermo-hygrometer suspended in the poultry 
house was used to measure relative humidity. The length of photoperiod was obtained daily from the Namibia Meteorological Service website. Each week eight cages were randomly selected using the simple random sampling procedure by generating eight random numbers between 1 and 200 in Microsoft Excel 2013. Cages corresponding to the random numbers generated were sampled for the study and all the 40 birds jointly housed were weighed on a weekly basis for the duration of the study. A sample of eggs and birds was weighed weekly. Sample size was determined using the standard formula for calculation (Putt et al., 1988):

$\mathrm{n}=\mathrm{Z}^{2} \times \mathrm{S}^{2} / \mathrm{d}^{2}$

Where:

$\mathrm{n}=$ sample size

$\mathrm{Z}=\mathrm{z}$ value at the desired confidence level. $(95 \%)$

$\mathrm{d}=$ the maximum difference to be tolerated between the sample mean and the true mean

$S^{2}=$ variance

The study commenced with 1000 birds that were brought in at 18 weeks of age at a cost of US\$5.62 per bird. During the study period, a total of 91 mortalities occurred. A total of 152,138 eggs were produced during the 27 -week study period. Each egg was sold at US\$0.078. Labourers worked for 56 hours per week payable at US\$3.15 per man-hour. The study birds received $875 \mathrm{~kg}$ of feed weekly at a cost of US\$58.59 per tonne. The total costs incurred in the enterprise were due to purchasing of birds, feed, mortalities and labour whilst the sole income was due to sale of eggs.

\subsection{Statistical analysis}

The Shapiro Wilk test showed that egg weight data had a normal distribution with a strong positive linear relationship between egg weight and $\mathrm{Z}$ scores (0.75). Likewise, there was a strong positive linear relationship between number of eggs/bird and $\mathrm{Z}$ scores $(0.85)$.

Pearson's correlation was performed to validate the association of various categories of age, ambient temperature, relative humidity and photoperiod with mean number of eggs and mean weight of eggs. Single factor ANOVA whereby $p \leq 0.05$ was considered significant. The Statistical Package for Social Sciences (SPSS) software version 25 was used in this study. The descriptions which were assigned to the ranges of the calculated values of correlation coefficients (r) are shown in Table 1.

Table 1: Descriptions assigned to the ranges of the values of correlation coefficients $(r)$

\begin{tabular}{ll}
\hline R value & Description \\
\hline 0 to 0.19 & very weak \\
0.2 to 0.39 & weak \\
0.4 to 0.59 & moderate \\
0.6 to 0.79 & strong \\
0.8 to 1.0 & very strong \\
\hline
\end{tabular}

\section{RESULTS}


The findings of this study are reported in three sections. In the first part, the significance and strength of the correlations of age of layers, ambient temperature, relative humidity, photoperiod to mean number of eggs per bird and mean weight of eggs was examined. The second part used single factor ANOVA and post hoc t-tests to further compare the categories showing significant effects on egg production and egg weight. In the third part, the profitability of this egg production enterprise under study was examined.

As shown in Table 2, only relative humidity showed a moderate negative correlation to the mean number of eggs and mean weight of eggs. Age of birds showed a moderate positive correlation with the mean number of eggs and a very strong positive correlation with the mean weight of eggs. Maximum diurnal ambient temperatures showed a weak positive correlation with the mean number of eggs and a strong positive correlation with the mean weight of eggs. Minimum diurnal ambient temperatures showed a moderate positive correlation with the mean number of eggs and a strong positive correlation with the mean weight of eggs. Average diurnal ambient temperatures showed a moderate positive correlation with the mean number of eggs and a strong positive correlation with the mean weight of eggs. Photoperiod showed a weak positive correlation with the mean number of eggs and a strong positive correlation with the mean weight of eggs. The results also showed a moderate positive correlation between age and the mean number of eggs and a very strong positive correlation with the mean weight of eggs.

Table 2: Strength and significance of the correlation between age, temperature, relative humidity, photoperiod and mean number of eggs / mean weight of eggs

\begin{tabular}{lll}
\hline Factor & Mean number of Eggs & Mean weight of eggs \\
\hline Age & & \\
$\quad R$ & 0.49 & 0.84 \\
$p$ value & $<0.01$ & $<0.001$ \\
\hline Maximum temperature & & \\
$R$ & 0.33 & 0.67 \\
$p$ value & $>0.05$ & $<0.001$ \\
\hline Minimum temperature & & \\
$R$ & 0.48 & 0.69 \\
$p$ value & $<0.05$ & $<0.001$ \\
\hline Average temperature & & \\
$R$ & 0.41 & 0.7 \\
$p$ value & $<0.05$ & $<0.001$ \\
\hline Relative humidity & & -0.51 \\
$R$ & -0.43 & $<0.01$ \\
$p$ value & $<0.05$ & \\
$r$ & & 0.7 \\
$p$ value & 0.34 & $<0.001$ \\
\hline Photoperiod & $>0.05$ &
\end{tabular}

As shown in Table 3, there was insufficient evidence to suggest the dependence of mean number of eggs per bird on age, temperature, humidity and photoperiod $(p>0.05)$. The mean egg weight, however, significantly increased as the birds advanced in age from 19 to 45 weeks (Table 4). Higher maximum diurnal temperatures ranging from 29 to $32.3^{\circ} \mathrm{C}$ were 
significantly associated with greater mean egg weight. Higher minimum diurnal temperatures ranging from 13.4 to $17.5^{\circ} \mathrm{C}$ were significantly associated with greater mean egg weight. Higher average diurnal temperatures ranging from 21.3 to $24.9^{\circ} \mathrm{C}$ were significantly associated with greater mean egg weight. Lower relative humidity $(<16 \%)$ was significantly associated with greater mean egg weight. Photoperiods greater than $11.61 \mathrm{hrs}$ were significantly associated with greater mean egg weight.

Table 3: Effect of age of bird, temperature, humidity and photoperiod on the mean number of eggs/bird and mean weight of eggs

\begin{tabular}{lccc}
\hline & Category & $\begin{array}{c}\text { Mean number of } \\
\text { eggs per bird }\end{array}$ & Mean egg weight (g) \\
\hline Age & 19 to 27 weeks & $0.73 \pm 0.11$ & $51.28 \pm 1.85$ \\
& 28 to 36 weeks & $0.82 \pm 0.05$ & $57.92 \pm 0.62$ \\
& 37 to 45 weeks & $0.92 \pm 0.01$ & $60.51 \pm 0.01$ \\
\hline Maximum temperature & 22.4 to $<25.7^{\circ} \mathrm{C}$ & $0.75 \pm 0.08$ & $52.7 \pm 1.56$ \\
& 25.7 to $<29.0^{\circ} \mathrm{C}$ & $0.84 \pm 0.06$ & $58.5 \pm 0.90$ \\
Minimum temperature & 29.0 to $32.3^{\circ} \mathrm{C}$ & $0.92 \pm 0.01$ & $60.44 \pm 0.05$ \\
\hline Average temperature & 5.2 to $<9.3$ & $0.63 \pm 0.15$ & $51.86 \pm 3.04$ \\
& 9.3 to $<13.4$ & $0.86 \pm 0.04$ & $56.15 \pm 1.05$ \\
& 13.4 to 17.5 & $0.9 \pm 0.01$ & $60.26 \pm 0.18$ \\
\hline Relative humidity & 13.9 to $<17.6^{\circ} \mathrm{C}$ & $0.71 \pm 0.11$ & $52.43 \pm 2.10$ \\
& 17.6 to $<21.3^{\circ} \mathrm{C}$ & $0.86 \pm 0.04$ & $57.51 \pm 0.94$ \\
& 21.3 to $24.9^{\circ} \mathrm{C}$ & $0.91 \pm 0.01$ & $60.42 \pm 0.06$ \\
\hline Photoperiod & $<16 \%$ & $0.91 \pm 0.01$ & $60.11 \pm 0.22$ \\
& $\geq 16 \%$ & $0.79 \pm 0.06$ & $55.08 \pm 1.25$ \\
\hline
\end{tabular}

Table 4: Cross-tabulation of mean egg weight according to age, temperature, humidity and photoperiod categories

\begin{tabular}{|c|c|c|c|c|}
\hline Parameter & \multicolumn{4}{|c|}{ Cross-tabulated mean egg weight ( $p$ value) } \\
\hline \multicolumn{5}{|l|}{ Age } \\
\hline & & 19 to 27 weeks & 28 to 36 weeks & 37 to 45 weeks \\
\hline & 19 to 27 weeks & - & $<0.001$ & $<0.001$ \\
\hline & 28 to 36 weeks & - & - & $<0.001$ \\
\hline & 37 to 45 weeks & - & - & - \\
\hline \multicolumn{5}{|c|}{ Maximum temperature } \\
\hline & & 22.4 to $<25.7^{\circ} \mathrm{C}$ & 25.7 to $<29.0^{\circ} \mathrm{C}$ & 29.0 to $32.3^{\circ} \mathrm{C}$ \\
\hline & 22.4 to $<25.7^{\circ} \mathrm{C}$ & - & $>0.05$ & $<0.001$ \\
\hline & 25.7 to $<29.0^{\circ} \mathrm{C}$ & - & - & $>0.05$ \\
\hline & 29.0 to $32.3^{\circ} \mathrm{C}$ & - & - & - \\
\hline \multicolumn{5}{|c|}{ Minimum temperature } \\
\hline & & 5.2 to $<9.3$ & 9.3 to $<13.4$ & 13.4 to 17.5 \\
\hline & 5.2 to $<9.3$ & - & $<0.01$ & $<0.01$ \\
\hline & 9.3 to $<13.4$ & - & - & $>0.05$ \\
\hline & 13.4 to 17.5 & - & - & - \\
\hline
\end{tabular}

Average temperature

\begin{tabular}{lccc} 
& 13.9 to $<17.6^{\circ} \mathrm{C}$ & 17.6 to $<21.3^{\circ} \mathrm{C}$ & 21.3 to $24.9^{\circ} \mathrm{C}$ \\
\cline { 2 - 4 } 13.9 to $<17.6^{\circ} \mathrm{C}$ & - & $>0.05$ & $<0.01$ \\
17.6 to $<21.3^{\circ} \mathrm{C}$ & - & - & $>0.05$
\end{tabular}


21.3 to $24.9^{\circ} \mathrm{C}$

\begin{tabular}{|c|c|c|c|c|}
\hline \multicolumn{5}{|l|}{ Relative humidity } \\
\hline & & $<16 \%$ & $\geq 16 \%$ & \\
\hline & $<16 \%$ & - & $<0.05$ & \\
\hline & $\geq 16 \%$ & - & - & \\
\hline \multicolumn{5}{|l|}{ Photoperiod } \\
\hline & & 10.75 to $<11.61 \mathrm{hrs}$ & 11.61 to $<12.47 \mathrm{hrs}$ & 12.47 to $\leq 13.33 \mathrm{hrs}$ \\
\hline & 10.75 to $<11.61 \mathrm{hrs}$ & - & $<0.001$ & $<0.001$ \\
\hline & 11.61 to $<12.47 \mathrm{hrs}$ & - & - & $>0.05$ \\
\hline & 12.47 to $\leq 13.33 \mathrm{hrs}$ & - & - & - \\
\hline
\end{tabular}

As shown in Table 5, the projected costs incurred by the enterprise were due to purchase of point-of-lay birds $(31.3 \%)$, labour $(51 \%)$ and feed $(14.8 \%)$ about halfway through the productive period. The total income from eggs was $88 \%$ of the total projected income and the potential salvage value of off-layers was $12 \%$ of the total projected income leaving the enterprise with a $42.3 \%$ profit. Mortalities accounted for $2.9 \%$ of the total costs.

Table 5: A summary of the financials of the enterprise under study 27 weeks into production

\begin{tabular}{llcl}
\hline & Costs (US\$) & Income (US\$) & $\begin{array}{l}\text { Profit } \\
\text { (US\$ }\end{array}$ \\
\hline 1000 birds at point-of-lay @ US\$5.62/bird & $5,620.52$ & - \\
Total feed cost by week 45weeks of age & $1,384.16$ & - & - \\
Total cost of 91 dead birds @ US\$5.62/bird by 45weeks of age & 512.38 & - & - \\
Total labour costs @ US\$176.49/week & $4,765.19$ & - & - \\
Total egg sales @ US\$0.078/egg & - & $11,866.76$ & - \\
Projected additional feed costs by 70weeks of age* & $1,281.63$ & - & - \\
Projected additional labour costs by 70weeks of age* & $4,410.21$ & - & - \\
Projected additional eggs sales by 70weeks of age* & - & $10,645.23$ & - \\
Projected income from sale of off-layers @ US\$3.58/bird* & - & $3,070.70$ & - \\
\hline Total & $\mathbf{1 7 , 9 7 4 . 0 9}$ & $\mathbf{2 5 , 5 8 2 . 6 9}$ & $\mathbf{7 , 6 0 8 . 6 0}$
\end{tabular}

*Projections were based on the assumptions that no further mortalities occurred and that productivity remained constant

\section{DISCUSSION}

The number of eggs showed weak correlation with almost every productivity parameter measured in this study (Table 2 and 3 ). Regardless of the age of the layer, maximum diurnal temperature, minimum diurnal temperature, average diurnal temperature and relative humidity the number of eggs never increased beyond $0.75-0.85$; and hence a weak association of the number of eggs and these parameters. There was insufficient evidence to suggest that the mean number of eggs/bird was dependent on age, temperature, humidity and photoperiod $(p>0.05)$. The mean egg weight, however, significantly increased as the birds advanced in age from 19 to 45 weeks $(p<0.001)$ (Table 2$)$.

The very strong positive correlation between age and mean egg weight as the birds increased in age from 19 to 45 weeks, as observed in this study, is not a new phenomenon and has been reported elsewhere (Padhi et al., 2013; Tůmová et al., 2017), including the 
developers of the breed which was used in the current study (Lohmann Tierzucht, 2018c). In the current study, the dramatic increase in weight with advancing age occurred between 19 and 27 weeks rather than after the 30 weeks reported in another study (Yi et al., 2014). This difference could be attributable to the different breeds which were used in the two studies.

The maximum diurnal ambient temperatures showed a weak positive correlation with the mean number of eggs $(r=0.33, p>0.05)$ and a strong positive correlation $(r=0.67$, $p<0.001$ ) with the mean weight of eggs (Table 1). Higher maximum diurnal temperatures ranging from 29 to $32.3^{\circ} \mathrm{C}$ were significantly associated with greater mean egg weight $(\mathrm{p}<0.001)$ (Table 2). The strong positive correlation of egg weight with maximum temperature begs an explanation. According to many authors (Abbas et al., 2011; Kumar et al., 2017; Oguntunji and Alabi, 2010; Talukder et al., 2010), elevated ambient temperatures of about $35^{\circ} \mathrm{C}$ have been found to significantly reduce egg weight, shell weight, shell thickness, albumen and egg yolk (Freitas et al., 2017; Yahav, 2000). According to some authors, ambient temperatures between $21^{\circ} \mathrm{C}$ and $26^{\circ} \mathrm{C}$ are ideal for egg production (Freitas et al., 2017). Therefore, temperatures higher than $27^{\circ} \mathrm{C}$ should have resulted in reduced feed intake and consequently reduced egg weights. It is paradoxical that such high ambient temperatures should give higher average egg weights. Perhaps, the Lohmann Brown is probably well adapted to the otherwise unfavourable maximum temperatures of central Namibia. This however, can only be ascertained by further studies focusing on these aspects.

The minimum diurnal ambient temperatures showed a moderate positive correlation with the mean number of eggs $(r=0.48, p<0.05)$ and a strong positive correlation $(r=0.69$, $p<0.001)$ with the mean weight of eggs. Minimum diurnal temperatures ranging from 13.4 to $17.5^{\circ} \mathrm{C}$ were significantly associated with greater mean egg weight $(\mathrm{p}<.01)$. These observations suggest that temperatures as low as $15^{\circ} \mathrm{C}$ could be ideal for layers (Kocaman et al., 2006). However, the fact that minimum temperatures at Farm A dip to as low as $5.2^{0} \mathrm{C}$ is a cause for concern.

Average diurnal ambient temperatures showed a strong positive correlation with the mean weight of eggs $(r=0.7, p<0.001)$. It can be observed that the Lohmann Brown layers' productivity was more responsive to the lower temperatures than to higher temperatures. A similar trend with temperatures was also reported in one study in which egg production was unaffected by a change ambient temperature from $25^{\circ} \mathrm{C}$ to $35^{\circ} \mathrm{C}$ (Yahav, 2000).

The results suggest that the farm experienced wide variations in ambient temperatures in its poultry house. The low temperatures which are normally experienced in winter nights should be mitigated against by providing heating. On the other hand, there seems to be no need to worry about higher maximum temperatures of up to $32.2^{\circ} \mathrm{C}$ since the findings of this study suggested that this had no effect on egg production. Therefore, in situations where resources are limited, top priority should be to protect the birds against low temperatures as long as water is provided ad libitum.

The results showed that there was a moderate negative correlation between the relative humidity and mean number of eggs $(r=-0.43, p<0.05)$ and mean weight of eggs $(r=$ $-0.51, p<0.01)$. The recorded relative humidity levels in the poultry house which ranged from $12 \%$ to $29 \%$ were nowhere near the generally accepted levels of between $40 \%$ and $80 \%$ (Freitas et al., 2017). From the results, only relative humidity showed a moderate negative correlation to the mean number of eggs $(r=-0.43, \mathrm{p}<0.05)$ and mean weight of eggs $(r=-$ $0.51, \mathrm{p}<0.01)$. However, lower relative humidity $(<16 \%)$ was significantly associated with greater mean egg weight $(\mathrm{p}<0.05)$. This suggests that decreasing humidity levels failed to lower egg weights. These findings support those from another study where a negative 
association between relative humidity and egg production was also observed (Kocaman et al., 2006). This is of significance in a semi-arid country like Namibia where humidity levels are generally low and it is desirable that this does not seem to reduce egg production or egg weights. It is also possible that the low humidity in a high temperature environment is advantageous to the birds as it favours evaporative cooling.

Photoperiod showed a weak positive correlation with the mean number of eggs $(r$ $=0.34, p>0.05)$ and a strong positive correlation with the mean weight of eggs $(r=0.7$, $p<0.001)$. The recommended photoperiod for laying Lohmann Brown hens is 12 hours (Lohmann Tierzucht, 2011). The photoperiod to which the birds in the current study were exposed to gradually increased from 10 to 16.9 hours per day. It was evident that photoperiods greater than $11.61 \mathrm{hrs}$ were significantly associated with greater mean egg weight $(\mathrm{p}<0.001)$. Therefore lighting periods as low as 11.61 hours per day still sufficed for Lohmann Brown layers in a semi-arid climate. Given that Namibia gets at least 10 hours of sunlight per day throughout the year, this study suggests that there is therefore no need to provide supplementary artificial lighting for Lohmann Brown layers under these conditions. Moreover, other studies have shown that feed intake in the laying period is not significantly affected by the rearing photoperiod for Lohmann Brown chickens (Lewis et al., 2010; Thiele, 2012).

The results of this study (Table 5) showed that the layer enterprise at Farm A potentially realised a gross profit of $42.3 \%$. This margin of profit is lower compared to other studies in Nigeria where profits ranged from 53\% to 58\% for small scale producers with similar flock sizes (Hamidu et al., 2015; Nalami et al., 2019). The lower profit margin in the current study could be attributed to the high input costs, especially labour costs which accounted for $51 \%$ of all input costs. In one study in Nigeria labour costs accounted for only $1 \%$ of the input costs (Nalami et al., 2019). Reducing the labour costs at Farm A should therefore improve profitability.

Namibia also relies on importing most of the ingredients used for animal feed processing, and this probably contributed to the high feed costs which were calculated at $14 \%$, although this is much lower than the $53.6 \%$ which was calculated by Nalami et al. (2019). However, this latter discrepancy could be due to the fact that the study by Nalami et al. (2019) took into account the feed used in raising the layer chicks, which was not the case in the current study because the birds were sourced at point-of-lay. The low prices at which the eggs were sold at the institution compared to grocery outlets could also have contributed to the lower profits. Since most of the income (88\%) was from egg sales, the low prices negatively impacted the profitability of the enterprise.

In spite of the lower margin of profit in this study compared to others, it is evident that layer production is profitable. Anyone going into Lohmann Brown layer production with minimum resources has a good chance of making a profit. Seeing that egg production accounted for $88 \%$ of the income, any factors affecting egg production are prone to have a profound effect on productivity. It is surprising to note that the Lohmann Brown layer is well adapted to produce within the ambient environmental temperatures and prevailing humidity in a semi-arid environment. The high maximum ambient temperatures during the day, the low humidity and abundant sunlight (photoperiod) did not have a significant effect on the number of eggs produced per bird. Moreover, if desired, the low minimum ambient temperature can easily be mitigated by providing heat during winter nights. Even though the age of birds, temperature, humidity and photoperiod had profound effects on egg weight, these factors did not affect the enterprise as the farm does not grade their eggs with a view to improving pricing. 
The authors conclude that Lohmann Brown layers perform well in semi-arid environmental conditions and perhaps in other areas of Namibia provided that extreme environmental conditions are avoided. The profitability of this enterprise was chiefly impacted by high input costs, especially labour and feed, and finding ways to reducing these costs is key to increasing profitability. Increasing the size of the flock is one feasible way of offsetting the high labour costs.

\section{ACKNOWLEDGEMENT}

The authors would like to sincerely thank the University of Namibia for allowing them to conduct this research as well as funding the publication of this manuscript.

\section{REFERENCES}

Abbas, T.E., Yousuf, M.M., Ahmed, M.E., Hassabo, A.A., 2011. Effect of fluctuating ambient temperature on the performance of laying hens in the closed poultry house. Res. Opin. Anim. Vet. Sci. 1, 254-257.

Bharali, D., Borah, D., Rajbonshi, P., Dutta, L.J., 2020. Study on adaptability , productive performance, economy and impact of Chara Chambelli duck in backyard system of rearing at Udalguri district of Assam. J. Entomol. Zool. Stud. 8, 1041-1043.

Cao, Y.J., Chen, C., Cranfield, J., Widowski, T., 2017. Market Responses to Information Conveying Mixed Messages - Prediction of Informational Impacts on Consumer Willingness to Pay for Eggs from Welfare Enhanced Cage Systems using Discrete Choice Experiments 1, in: Agricultural and Applied Economics Association Annual Meeting. Chicago, pp. 1-24.

CocciForum, 2019. Technically Speaking [WWW Document]. Poult. Site. URL https://thepoultrysite.com/cocciforum/issue7/48/technically-speaking (accessed 4.19.19).

Etches, R.J., 1996. Reproduction in poultry., Reproduction in poultry. CAB INTERNATIONAL, Wallingford, UK.

Farghly, M.F.A., El-Garhy, O.H., Ali, R., 2017. Application of Flashed Lighting Program in Naked Neck Chickens (Sharkasi) Management. Egypt. Poult. Sci. J. 37, 1063-1089. https://doi.org/10.21608/epsj.2017.5380

Freitas, L.C.S.R., Tinôco, I.F.F., Baêta, F.C., Barbari, M., Conti, L., Teles Júnior, C.G.S., Cândido, M.G.L., Morais, C. V., Sousa, F.C., 2017. Correlation between egg quality parameters, housing thermal conditions and age of laying hens. Agron. Res. 15, 687693.

Guo, B., Zhao, S., Shao, X., Ding, W., Shi, Z., Tang, Z., 2019. Analyses of mathematical models for Yangzhou geese egg-laying curves. Anim. Reprod. Sci. 203, 10-24. https://doi.org/10.1016/j.anireprosci.2019.02.003

Hamidu, B., Abdulhamid, A., Atman, F.M., Usman, A.B., Joseph, U.G., 2015. Profitability and resource use efficiency of layers production in Bauchi Metropolis of Bauch State. ATBU, J. Sci. Technol. Educ. 3, 110-120.

Han, S., Wang, Y., Liu, L., Li, D., Liu, Z., Shen, X., Xu, H., Zhao, X., Zhu, Q., Yin, H., 
2017. Influence of three lighting regimes during ten weeks growth phase on laying performance, plasma levels- and tissue specific gene expression- of reproductive hormones in Pengxian yellow pullets. PLoS One 12, 1-11. https://doi.org/10.1371/journal.pone.0177358

Holik, V., 2010. Managing heat stress - Part 1 - Layers respond to hot climatic conditions [WWW Document]. Poult. World. URL https://www.poultryworld.net/Breeders/General/2010/3/Managing-heat-stress---Part-1--Layers-respond-to-hot-climatic-conditions-WP007271W/ (accessed 4.19.19).

Hulzebosch, J., 2019. Climate in poultry houses [WWW Document]. Poult. Hub. URL http://www.poultryhub.org/production/husbandry-management/housingenvironment/climate-in-poultry-houses/ (accessed 4.19.19).

Idowu, P.A., Mpayipheli, M., Muchenje, V., 2019. A Survey Study on Productive and Reproductive Performance of Indigenous Poultry.

Info-Namibia, 2018. Climate and Weather of Namibia [WWW Document]. URL https://www.info-namibia.com/info/namibia-weather (accessed 12.24.18).

Jácome, I.M.T.D., Rossi, L.A., Borille, R., 2014. Influence of Artificial Lighting on the Performance and Egg Quality of Commercial Layers: a Review. Brazillian J. Poult. Sci. 16, 337-344. https://doi.org/http://dx.doi.org/10.1590/1516-635x1604337-344

Janczak, A.M., Riber, A.B., 2015. Review of rearing-related factors affecting the welfare of laying hens. Poult. Sci. 94, 1454-1469. https://doi.org/10.3382/ps/pev123

John-Jaja, S.A., Abdullah, A.-R., Nwokolo, S.C., 2016. Effects of age variance on repeatability estimates of egg dimensions of Bovan Nera Black laying chickens. J. Genet. Eng. Biotechnol. 14, 219-226. https://doi.org/10.1016/j.jgeb.2016.06.003

Johnston, J.D., 2004. Photoperiodic regulation of prolactin secretion: changes in intrapituitary signalling and lactotroph heterogeneity. J. Endocrinol. 180, 351-6.

Kandiwa, E., Mushonga, B., Samkange, A., Bishi, A., Nyoni, N., 2018. Retrospective study on small ruminants losses in a farm of Namibia. Indian J. Small Ruminants 24, 115-120. https://doi.org/10.5958/0973-9718.2018.00003.X

Kocaman, B., Esenbuga, N., Yildiz, A., Laçin, E., Macit, M., 2006. Effect of environmental conditions in poultry houses on the performance of laying hens. Int. J. Poult. Sci. 5, 2630. https://doi.org/10.3923/ijps.2006.26.30

Kshash, B., 2019. Constraints Facing Poultry Producers in Iraq. J. Agric. Ext. 23, 90-100. https://doi.org/https://dx.doi.org/10.4314/jae.v23i2.10

Küçükyilmaz, K., Bozkurt, M., Herken, E.N., Çinar, M., Çatl, A.U., Bintaş, E., Çöven, F., 2012. Effects of rearing systems on performance, egg characteristics and immune response in two layer hen genotype. Asian-Australasian J. Anim. Sci. 25, 559-568. https://doi.org/10.5713/ajas.2011.11382

Kumar, M., Dalal, D.S., Ratwan, P., Yadav, A.S., 2017. Strategies to Minimize Heat Stress in Broiler and Layer Chickens. Res. Rev. J. Dairy Sci. Technol. 6, 26-30.

Lewis, P.D., Danisman, R., Gous, R.M., 2010. Photoperiods for broiler breeder females during the laying period. Poult. Sci. 89, 108-114. https://doi.org/10.3382/ps.2009-00312 
Lohmann Tierzucht, 2018a. History - LOHMANN TIERZUCHT GmbH [WWW Document]. Lohmann Tierzucht. URL https://www.ltz.de/en/company/history.php (accessed 4.19.19).

Lohmann Tierzucht, 2018b. Management Guide: Hot Climate [WWW Document]. Lohmann Tierzucht. URL https://www.ltz.de/en (accessed 12.17.18).

Lohmann Tierzucht, 2018c. Lohmann Brown-Classic: Cage Housing Performance Data [WWW Document]. URL http://www.ltz.de/en/layers/alternative-housing/lohmann-lslclassic.php (accessed 12.23.18).

Lohmann Tierzucht, 2011. Management Guide Hot Climate - Heat stress under control 48.

Mendelsohn, J., Jarvis, A., Roberts, C., Robertson, T., 2002. Atlas of Namibia. A Portrait of the Land and its People. David Philip Publishers, Cape Town.

https://doi.org/10.1002/mmnz.20040800111

Nalami, Z.M., Olayiwola, S.A., Beli, S.A., 2019. Profitability analysis of poultry layers production in three local government areas of Kano State - Nigeria. Sci. Pap. Ser. Manag. Econ. Eng. Agric. Rural Dev. 19, 291-295.

Oguntunji, A.O., Alabi, O.M., 2010. Influence of high environmental temperature on egg production and shell quality: A review. Worlds. Poult. Sci. J. 66, 739-750. https://doi.org/10.1017/S004393391000070X

Padhi, M.K., Chatterjee, R.N., Haunshi, S., Rajkumar, U., 2013. Effect of age on egg quality in chicken Animal genetics and breeding View project. Indian J. Poult. Sci. 48, $122-$ 125.

Petrus, N.P., Kangootui, K., Kandiwa, E., Madzingira, O., Mushonga, B., 2019. Relationship of Age and Live weight to Linear Body Traits in Female Intensively Reared Boschveld Chicken in Namibia. Int. J. Poult. Sci. CC, CC-CC. https://doi.org/10.3923/ijps.2019.483.491

Putt, S.N.H., Shaw, A.P.M., Woods, A.J., Tyler, L., James, A.D., 1988. Epidemiology and economics in Africa, 1st ed. ILCA, Addis Ababa, Ethiopia.

Rubinoff, I., 2014. Lighting Pullets and Layers, Genetic Excellence.

Sallam, E.A., Mohammed, L.S., Azam, A.E., 2019. Factors Affecting Productive and Economic Efficiency of Hy-Line Layer Breed Under Egyptian Condition. Alexandria J. Vet. Sci. 63, 14-22. https://doi.org/10.5455/ajvs.71805

Skoglund, W.C., Whittaker, D., 1980. Interrupted Lighting Programs for Brown Egg Breeds. Poult. Sci. 59, 2397-2399. https://doi.org/https://doi.org/10.3382/ps.0592397

Talukder, S., Islam, T., Sarker, S., Islam, M.M., 2010. Effects of environment on layer performance. J. Bangladesh Agric. Univ. 8, 253-258. https://doi.org/10.1016/B978-07216-9323-1.50059-3

Thiele, H.H., 2012. Management tools to influence egg weight in commercial layers. Lohmann Inf. 47, 21-31.

Travel, A., Nys, Y., Bain, M., 2011. Effect of hen age, moult, laying environment and egg storage on egg quality, in: Y. Nys, Bain, M., Van-Immerseel, F. (Eds.), Improving the Safety and Quality of Eggs and Egg Products. Volume 1. Woodhead Publishing 
Limited, Cambridge, UK, pp. 300-329.

Tůmová, E., Uhlíŕová, L., Tůma, R., Chodová, D., Máchal, L., 2017. Age related changes in laying pattern and egg weight of different laying hen genotypes. Anim. Reprod. Sci. 183, 21-26. https://doi.org/10.1016/j.anireprosci.2017.06.006

Udeh, I., 2010. Repeatability of egg number and egg weight in two strains of layer type chicken. Int. J. Poult. Sci. 9, 675-677. https://doi.org/10.3923/ijps.2010.675.677

Vlčková, J., Tůmová, E., Ketta, M., Englmaierová, M., Chodová, D., 2018. Effect of housing system and age of laying hens on eggshell quality, microbial contamination, and penetration of microorganisms into eggs. Czech J. Anim. Sci. 63, 51-60. https://doi.org/10.17221/77/2017-CJAS

Yahav, S., 2000. Relative humidity at moderate ambient temperatures: Its effect on male broiler chickens and turkeys. Br. Poult. Sci. 41, 94-100. https://doi.org/10.1080/00071660086475

Yi, G., Liu, W., Li, J., Zheng, J., Qu, L., Xu, G., Yang, N., 2014. Genetic analysis for dynamic changes of egg weight in 2 chicken lines. Poult. Sci. 93, 2963-2969. https://doi.org/10.3382/ps.2014-04178

Yusuf, S.F.G., Lategan, F.S., Masika, P.J., 2014. Characterization of Indigenous Poultry Production Systems in the Nkonkobe Municipality, Eastern Cape Province South Africa. J. Agric. Sci. 5, 31-44.

Zemková, L., Simeonovová, J., Lichovníková, M., Somerlíková, K., 2007. The effects of housing systems and age of hens on the weight and cholesterol concentration of the egg. Czech J. Anim. Sci. 52, 110-115. 